\title{
O IMPACTO DA ACELERAÇÃO TEMPO-ESPAÇO NAS RELAÇÕES DE PRODUÇÃO
}

THE IMPACT OF THE TIME-SPACE ACCELERATION IN THE RELATIONS OF PRODUCTION

\section{EL IMPACTO DE LA ACELERACIÓN TIEMPO-ESPACIO EN LAS RELACIONES DE PRODUCCIÓN}

\author{
Osterne Nonato Maia Filho \\ Doutor e Mestre em Educação, Bacharel e Licenciado em Psiologia. \\ Professor dos cursos de psicologia da UECE e da UNIFOR e dos Programas de Pós-graduação em Educação da UFC e da UECE. \\ osterne_filho@uol.com.br \\ Hamilton Viana Chaves \\ Doutor em educação, mestre em psicologia, especialista em psicopedagogia. \\ Professor do curso de psicologia da Unifor e psicólogo do IFCE. \\ hamilton@unifor.br \\ Luis Távora Furtado Ribeiro \\ Doutor em sociologia, mestre em educação e graduado em sociologia. \\ Professor do PPG educação da UFC. \\ luistavora@uol.com.br \\ Natalia Dias de Sousa \\ Analista de recursos humanos e psicóloga. \\ nataliadias87.nd@gmail.com
}

RESUMO: Tempo e espaço são categorias que se transformam no curso histórico da humanidade. Têm a ver com as transformações sociais decorrentes das modificações experimentadas nos diferentes modos de produção. $\mathrm{Na}$ contemporaneidade, marcada pelas relações de produção erigidas e coordenadas pelo capital, como se dão as vivências temporais e espaciais nas relações sociais? Este artigo tem como objetivo fazer um estudo exploratório sobre a evolução dos modos de produção e as implicações da aceleração tempo-espaço nas relações de produção. Trata-se de um estudo descritivo e analítico de cunho bibliográfico, baseado nos pressupostos do materialismo histórico e dialético. $O$ fenômeno da aceleração tempo-espaço contribui para o enfraquecimento da identidade cultural, ou seja, no esmaecimento da identificação com o lugar em que se nasceu e se criou, pois o espaço não pode ser mais definido como fixo e a mudança do tempo faz com que as pessoas tenham acesso a outros lugares. PALAVRAS-CHAVE: Modo de Produção. Aceleração Tempo-Espaço. Relações de Produção.

ABSTRACT: Time and space are categories that are transformed in the historical course of humanity. This is related to the social transformations caused by the changes experienced in different modes of production. In contemporaneity, marked by production relations constructed and coordinated by the capital, how are the temporal and spatial experiences in social relationships? This article aims to make an exploratory study about the modes of production evolution and the implications of the acceleration time-space in the relations of production. It is a descriptive and analytical study of bibliographic nature, based on assumptions of dialectical and historical materialism. The phenomenon of the acceleration in time-space contributes to the weakening of cultural identity, which means the fading of identification with the place where one was born and raised, because space can no longer be defined as fixed, and the shift of time makes people have access to other places.

KEYWORDS: Mode of production. Acceleration in time-space. Relations of production.

RESUMEN: Tiempo y espacio son categorías que cambian en el curso de la historia de la humanidad. Están relacionadas con las transformaciones sociales que surgen de los cambios experimentados en los diferentes modos de producción. En la contemporaneidad, marcada por las relaciones de producción coordinadas por el capital, como son las experiencias temporales y espaciales en las relaciones sociales? Este trabajo de investigación tiene como objetivo hacer un estudio exploratorio sobre la evolución de los modos de producción y las implicaciones de aceleración del espacio-tiempo en las relaciones de producción. Se trata de un estudio descriptivo y analítico de carácter bibliográfico, basado en fundamentos del materialismo dialéctico e histórico. El fenómeno de la aceleración del tiempo-espacio contribuye al debilitamiento de la identidad cultural, es decir, el desvanecimiento de la identificación con el lugar donde nació y se crió, ya que el espacio no puede ser definido como fijo, y el cambio de marcas de tiempo que la gente tenga acceso a otros lugares.

PALABRAS CLAVE: Modo de producción. La aceleración del tiempo-espacio. Relaciones de Producción.

$\overline{\text { Artigo recebido em maio de } 2014}$

Aprovado em julho de 2014

Cad. Pes., São Luís, v. 21, n. 2, mai./ago. 2014 
O IMPACTO DA ACELERAÇÃO | Osterne Filho et al.

\section{1 | Introdução}

Para entender as relações de trabalho e as formas de construção das identidades na postulada pós-modernidade, visto que esta última categoria está longe de ser consensualmente aceita pela ciência sociológica, o presente ensaio visa contribuir com o estudo de dois conceitos antes vistos como naturais, porém, agora, percebidos como resultantes das relações sociais de produção: o tempo e o espaço.

Harvey (2000) descreve o tempo e o espaço através de uma perspectiva materialista e dialética, visto que acredita que ambos servem à reprodução da vida social e são constituídos através de práticas e processos materiais. Para o autor, em cada época há uma maneira diferente de experienciar estas categorias, ou seja, os diversos modos de produção concatenam particularidades do tempo e do espaço vividos.

Com o modo de produção capitalista, principalmente após a mudança para o modelo de acumulação flexível do capital, ocorre uma modificação não somente na forma de se vivenciar o trabalho, mas também no sentido de configurar e conceber as dimensões temporal e espacial. Nas palavras de Castells (2006), o mundo encolheu em uma aldeia global, onde para falar com pessoas do outro lado do planeta é preciso somente um aparelho celular. Além do que, o deslocamento espacial e a comunicação instantânea, não só de e entre pessoas, mas de grupos e corporações, ficou muito mais rápido e prático, principalmente, para quem detém o capital.

Para Hall (1992), as mudanças ocorridas nas formas de vivenciar o tempo e o espaço não impactam somente nas questões do mundo do trabalho, mas trazem modificações também para a composição das identidades, que parecem ser erigidas na mesma velocidade que uma viagem, uma novela ou uma eleição. Consequentemente, tal celeridade gera impacto nas relações de produção, levando-se à indagação sobre como esta ocorre.

A análise ora apresentada referencia-se na ideia de que a sociedade atual é decorrente e determinada pelas configurações históricas vivenciadas no passado e que se modifica e transforma-se constantemente, em virtude de leis internas explicadas por relações de poder, lutas e contradições.

$\mathrm{Na}$ contemporaneidade, marcada pelas relações de produção erigidas e coordenadas pelo capital, como se dão as vivências temporais e espaciais nas relações sociais? Este artigo tem como objetivo fazer um estudo exploratório sobre a evolução dos modos de produção e as implicações da aceleração tempo-espaço nas relações de produção. Trata-se de um estudo descritivo e analítico de cunho bibliográfico, baseado nos pressupostos do materialismo histórico e dialético. A discussão inicia-se com um breve levantamento dos modos de produção vivenciados pela humanidade. Em seguida, discutiremos o capitalismo na contemporaneidade e as principais mudanças sociais advindas com ele, destacando o impacto da aceleração tempo-espaço nas relações de produção.

\section{2 | DO MODO PRIMITIVO AO FEUDAL}

A forma como a sociedade produz, utiliza e distribui os bens e serviços necessários ao funcionamento social caracteriza o modo de produção. Santos (1999, p.6), baseados em Karl Marx, afirma que à medida que a sociedade evolui, o homem participa de um processo único, que envolve "formas materiais de produção, relações dos homens entre si e com as coisas (naturais e artificiais) e os seus próprios modos de ser, isto é, as maneiras como os indivíduos expressam sua vida". Há, portanto, duas grandes dimensões em que se manifestam o modo de produção na leitura marxista: o desenvolvimento das forças produtivas enquanto a manifestação das "formas 
O IMPACTO DA ACELERAÇÃO | Osterne Filho et al.

materiais de produção"; e o desenvolvimento e manifestação das relações de produção, das "relações dos homens entre si" e seus "próprios modos de ser".

Santos (1999) ainda destaca que a história da humanidade é delineada e determinada a partir dos diferentes modos de produção, fato que pode ser percebido pelo surgimento de novos instrumentos e formas de trabalho e novas práticas sociais a eles associados. A vida em sociedade seria marcada pela complexa renovação destes modos de produção de riqueza e de relações sociais a ela associadas e a cada novo modo criado.

Uma determinada etapa de desenvolvimento das forças produtivas e das relações de produção associadas à organização socioeconômica, afirma Marzzitelli (2011), forma o modo de produção. Identificam-se assim, no decorrer da história da sociedade, seis etapas: o primitivo, o asiático, o escravista, o feudal, o capitalista e o comunista. A transição entre eles ocorre quando as forças produtivas entram em choque com as relações sociais de produção, de forma que as primeiras não conseguem continuar se desenvolvendo plenamente. Assim, dialeticamente, esses fenômenos são partes integrantes de um mesmo modo de produção, logo não existem separadamente.

Quando um modo de produção novo se desenvolve, assumindo um papel predominante em determinada sociedade, o antigo entra em declínio. Todavia, este último continua existindo subsumido pelo modo mais complexo, especialmente em sociedades onde não surgiram condições econômicas e sociais que propiciaram a transição. Isto possibilita que existam mais de um modo de produção em determinada época.

Com o surgimento da sociedade humana tem-se o primeiro modo de produção, denominado primitivo. Segundo Engels (1987), no início da sociedade os homens viviam como animais predatórios: para alimentarem-se e garantir suas existências eles caçavam, pescavam, colhiam frutos silvestres e chegavam a matar outros congêneres. Eles não ficavam fixos em um determinado espaço, pois, uma vez que acabavam os suprimentos do local, logo voltavam à procura de um novo lugar, já que o desenvolvimento das forças produtivas ainda não viabilizava o domínio da terra.

Na medida em que o homem foi desenvolvendo técnicas e habilidades particulares, passou a inventar instrumentos, como armas e meios de transportes que auxiliaram na fixação em terras férteis, especialmente aquelas próximas a mananciais de água, sendo possível a domesticação de animais e o desenvolvimento da agricultura, caracterizando o fim do nomadismo.

Para Menegasso (1998) o modo de produção primitivo é característico da época pré-histórica, pois neste período o trabalho aparece somente como fonte de subsistência, já que através da caça e da extração de raízes e depois da agricultura e pastoreio, tudo que o homem produzia era para seu próprio consumo e garantia da sua sobrevivência. Quando estas necessidades foram sendo supridas foi possível ampliar as relações sociais de produção, determinando assim, o início das formas de trabalho mais complexas.

Nesse momento, começou-se a produzir excedentes; o que se produzia era mais que suficiente para suprir as necessidades básicas, logo se tornou possível trocar os bens excedentes por materiais diversos. Neste momento, segundo Lessa e Tonet (2008), iniciou-se a exploração do homem pelo homem, possibilitando o surgimento das classes sociais e a mudança do modo de produção primitivo para os dois modos de produção que o sucederiam: o asiático e o escravista.

O modo de produção asiático foi predominante na região compreendida entre o Oriente Médio e a China, e também nas civilizações maias e astecas nas Américas; a descoberta da agricultura e da pecuária foi fundamental em seu desenvolvimento. Neste modelo econômico ocorria a exploração por parte da classe dominante que se apropriava, através dos impostos, do que era produzido nas aldeias, usando muitas vezes, de exércitos para o seu recolhimento. 
O IMPACTO DA ACELERAÇÃO | Osterne Filho et al.

Para que fosse possível a exploração por parte da classe dominante, foram criados novos complexos sociais. Os principais foram o Estado e o Direito. Segundo Marx (1997), o Estado é a organização da classe dominante em poder político, que para existir se apoia em um conjunto de instrumentos repressivos tais como o exército, a polícia, as leis, o funcionalismo público, entre outros. Entende-se também que o Estado, neste caso, nada mais é do que um instrumento de dominação de classe.

Entretanto, segundo Antunes (2007, p. 5), Marx também explicou que foi necessário o surgimento do Estado para unir centenas de pessoas na realização de trabalhos para um bem comum e que sem esta unidade superior os povos continuariam dispersos e não seria possível "suprir a necessidade de produção e reprodução da vida material da comunidade nem também de aparecer frente ao exterior como unidade local protegida por uma comunidade superior".

Esta afirmação é baseada nos grandes empreendimentos que o Estado organizava na época, pois este modo de produção era característico especialmente de regiões cujo solo disponível para agricultura era pouco e a densidade populacional elevada. Para uma produção adequada era necessário o cultivo de cereais em terrenos alagados, o que exigia enormes esforços para a construção de diques, represas e canais de irrigação. Desta forma, o Estado era responsável por recrutar mão de obra e custear os empreendimentos e, quando uma aldeia atingia o limite de produção, outra aldeia era fundada com o mesmo padrão da inicial.

O outro complexo social criado, o Direito, tinha como função, segundo Lessa e Tonet (2008, p. 21), "[...] regulamentar a vida social por meio de leis que jamais ultrapassem a dominação de classe". Como agora os indivíduos estavam divididos em classes, os interesses se tornaram divergentes, o que dava ao Direito o papel de evitar que as classes entrassem em conflitos.

O modo de produção escravista se desenvolveu concomitante ao asiático, porém foi mais comum em sociedades como a grega e a romana. Durante a antiguidade o modo de produção escravista vigorou, porém diferentemente de outras épocas, este não era uma forma de obter mão de obra barata, e sim, uma maneira de manter os indivíduos afastados da situação que permitisse se deixar escravizar pelas necessidades. De fato, neste período, o trabalho era tido como labor e significava ser escravizado pela necessidade: a escravidão era inerente a certas condições de existência da vida humana.

Nas sociedades escravistas existiam duas classes sociais distintas, os senhores de escravos e os escravos. Tudo que era produzido pelos escravos pertencia ao seu senhor (dominus), assim não havia interesse por parte dos escravos em aumentar a produção ou aperfeiçoar suas técnicas. Desta forma, a única maneira que os senhores tinham de ampliar suas riquezas era adquirindo mais escravos. Para isto entravam em conflito bélico com diversos impérios e tornavam escravos os prisioneiros de guerra.

Menegasso (1998) afirma que chegou um tempo que em Atenas existiam 21.000 cidadãos e 400.000 escravos, o que gerou medo, pois se os escravos se revoltassem não haveria como somente os senhores lidarem com a situação. Para se protegerem e evitarem futuras rebeliões, os senhores uniram-se e contrataram funcionários públicos que deviam recolher todo ano o imposto de cada um deles; com isto, o funcionalismo administraria o dinheiro, de forma a manter um exército.

Como forma de fazer a mediação entre os interesses dos senhores e normatizar uma sociedade formada por contradições entre estes e os escravos, que possuíam interesses distintos, o Direito também é introduzido.

Foi assim que, tal como no modo de produção asiático, as sociedades escravistas também desenvolveram o Estado e o Direito. E exatamente com a mesma função social das 
O IMPACTO DA ACELERAÇÃO | Osterne Filho et al.

\begin{abstract}
sociedades asiáticas: manter os trabalhadores em submissão, reprimir suas revoltas. Propriedade privada, Estado e Direito são, portanto, relações sociais que surgiram e, veremos se desenvolveram conjuntamente. Nenhum deles existe sem os outros dois, por mais que sejam diferentes as inter-relações que estabeleçam entre si em cada modo de produção. (LESSA; TONET, 2008, p. 23).
\end{abstract}

O crescimento do número de escravos acarretava a ampliação do exército e do Estado, gerando aumento nos impostos. Com o tempo, os custos eram tantos que os senhores não tinham mais como pagá-los, gerando revoltas no exército, nos funcionários públicos, assim como o aumento da corrupção. Como consequência, os escravos começaram a se rebelar e os povos vizinhos passaram a invadir os impérios constituídos.

Pelo fato de a classe dominante não ter conseguido maneiras de reestruturar o modo de produção escravista, este entrou em crise, mesmo sem uma classe revolucionária que guiasse a sociedade para um novo modelo alternativo que solucionasse os problemas coletivos. Como consequência, levou mais de três séculos a transição do escravismo para o feudalismo, o que ocorreu de forma lenta e caótica.

Tendo em vista a sua estruturação morosa, desordenada e fragmentada, o feudalismo ocorreu de maneira diferenciada em cada lugar. Entretanto, a principal característica do feudalismo era a organização das terras propícias à agricultura em feudos, que consistiam em unidades autossuficientes, que também serviam como base de forças militares próprias.

Outra característica básica do feudalismo era o sistema de produção voltado para os valoresde-uso, pois não havia interesse em produzir excedentes. As terras cultivadas eram divididas em sistema de faixas espalhadas e os arrendatários trabalhavam não só nas terras arrendadas, mas também, nas terras do senhor; de tudo que era produzido ema parte era dos servos e outra dos senhores, sendo a destes últimos a maior parcela. Não existiam estruturas políticas formando países ou mesmo um governo central e como os feudos eram autossuficientes, praticamente inexistia o comércio.

Diferente do modelo escravista, em que os escravos não tinham interesse em aumentar a produção, uma vez que nada que produziam ficava para eles, os servos dos feudos, por ficar com uma parte da produção, se esforçaram por melhorar o sistema de produção. Lessa e Tonet (2008, p. 37) ainda afirmam que como "[...] resultado desse interesse, começaram a desenvolver novas ferramentas, novas técnicas produtivas, novas formas de organização do trabalho coletivo, aprimoraram as sementes, melhoraram as técnicas de preservação do solo." Com o tempo a produção aumentou, e devido a melhor alimentação, cresceu também a população. Contudo, essa conjuntura fez com que os feudos entrassem em crise, uma vez que produziam mais do que podiam consumir, assim como possuíam um número de servos maior do que suas necessidades.

Diante dessa situação, a solução encontrada pelos senhores feudais foi romper com os servos, expulsando-os das terras em que eles estavam sobrando. Para sobreviver, estes passaram a roubar e a efetuar trocas dos produtos obtidos com outros servos. Como estava sendo produzidos excedentes muitos tinham o que trocar, o que resultou no surgimento de rotas comerciais e no renascimento de cidades que se desenvolveram em quase toda a Europa.

Neste período, começaram a surgir diversos tipos de trabalhos: quem trabalhava na terra passou aos ofícios de padeiro, de sapateiro, de ferreiro, entre outros. O significado do trabalho passou do caráter de redenção para o de realização pessoal, uma vez que as configurações se transformaram em função das novas posturas adotadas. Se ainda não se pode falar na formação de Estados nacionalistas (BHABHA, 1997), a distribuição espacial das cidades e os deslocamen tos pelas rotas de comércio dimensionadas por unidades de tempo possibilitaram que houvesse também, modificações nas identidades culturais determinadas pelas afinidades laborais. 
O IMPACTO DA ACELERAÇÃO | Osterne Filho et al.

\section{3 | 0 MODO DE PRODUÇÃO CAPITALISTA E A MODERNIDADE}

Com a crise dos feudos e o desenvolvimento das cidades surgem duas novas classes sociais: os artesãos e os comerciantes, sendo estes últimos também chamados de burgueses. A classe burguesa, não se contentando com o comércio local, se expandiu por toda Europa, e, depois, com as grandes navegações, por todo o mundo.

Neste momento, abriu-se espaço para o surgimento de um novo modo de produção, o capitalista. É com a evolução do capitalismo que a sociedade passou a ser dividida em burguesia e proletariado.

Com o avanço da industrialização não apenas o trabalho passou a ter significado diferente, como a relação que os indivíduos estabeleciam com ele passou a ser distinta, agora governada pelo mundo das mercadorias. Destaca Fernandes (2001, p. 8) que:

Em essência o capitalismo é um sistema de mercantilização universal e de produção de mais-valia. Ele mercantiliza as relações, as pessoas e as coisas. Ao mesmo tempo, pois, mercantiliza a força de trabalho, a energia humana que produz valor. Por isso mesmo, transforma as próprias pessoas em mercadorias, tornando-as adjetivas de sua força de trabalho.

Podemos perceber as diferenças do modo de produção capitalista em relação aos demais, pois neste as mercadorias estão para além de objetos em si, já que o próprio trabalhador também se transforma em mercadoria uma vez que passa a vender sua força de trabalho. Porém, a principal distinção é a produção e acumulação de mais-valia, que é o fim último do capitalismo.

Para que ocorra produção de mais-valia é preciso que a força de trabalho, que é comprada pelo capitalista, produza além do que lhe é pago, uma vez que esta é a diferença que existe entre o produto final e a soma da matéria prima e dos recursos utilizados para a produção, incluindo a força de trabalho.

\footnotetext{
O segredo da acumulação capitalista, pois, é a diferença entre o trabalho necessário à reprodução da vida do operário (o que é pago) e o trabalho excedente, que o trabalhador é obrigado a realizar (não pago). É o trabalho excedente que produz mais-valia; quando resulta da extensão da jornada de trabalho, produz a mais-valia absoluta, ao passo que produz mais-valia relativa quando resulta da potenciação da produtividade da força de trabalho, pela tecnologia, divisão social do trabalho ou outras forças produtivas combinadas.

(FERNANDES, 2001, p. 19).
}

Foram criadas ao longo dos últimos séculos várias formas de administração do trabalho para maximizar os resultados do capital, ou seja, a criação de mais-valia. Entre elas merecem destaque o taylorismo, o fordismo e o toyotismo.

Salienta Tenório (2011) que o taylorismo, criado pelo engenheiro Frederick Taylor, tinha sua forma de produção voltada ao estudo do tempo e movimento, ou seja, eram escolhidos trabalhadores para realizarem atividades específicas e estes eram treinados, de forma que ficassem mais disciplinados, realizando maior quantidade de movimentos determinados em um menor período de tempo.

O fordismo surgiu como um modelo de organização da produção, complementar ao taylorismo e que implicou num aprofundamento do controle do trabalho, a partir de uma nova organização espacial e temporal dos processos laborais. Este dividia o trabalho de forma que as atividades a serem realizadas pelos operários fossem extremamente simples, pois se acreditava que quanto 


\section{O IMPACTO DA ACELERAÇÃO | Osterne Filho et al.}

mais elementares fossem as atividades, maior seria a produtividade. Este modelo iniciou-se dentro de fábricas automobilísticas nos Estados Unidos e expandiu-se para todos os processos industriais nos principais países capitalistas, chegando a ampliar-se também para o setor de serviços.

A primeira geração fordista foi exitosa, a segunda, entretanto, não estava disposta a submeter-se às condições de trabalho oferecidas apenas para aumentar seu poder de compra. Antunes (2000, p.42) admite que

[...] ela não se encontrava disposta a 'perder sua vida para ganhá-la': a trocar o trabalho e uma existência desprovida de sentido pelo simples crescimento de seu 'poder de compra', privando-se de ser por um excedente de ter. Em suma, a satisfazer-se com os termos do compromisso fordista, assumido pela geração anterior.

Na década de 1970, começa uma crise estrutural no modelo de acumulação de capital fordista. Esta crise, segundo Harvey (2000), ocorreu principalmente devido à rigidez do modelo fordista. Existiram, porém, outros fatores tais como a decisão da Organização dos Países Produtores de Petróleo (OPEP) de aumentar o preço de seu produto; a determinação árabe de suspender o fornecimento de petróleo para o ocidente durante a guerra árabe-israelense, em 1973; o surgimento da concorrência japonesa com um novo modelo de gestão (o toyotismo) na produção automobilística; as mudanças tecnológicas e as desigualdades entre os setores de trabalho no interior do sistema fordista.

Com este novo cenário, o capital precisou se reestruturar para continuar sendo o modo de produção vigente, o que fez surgirem diversas transformações no processo produtivo, se destacando o modelo japonês (toyotismo).

Opondo-se ao contra-poder que emergia das lutas sociais, o capital iniciou um processo de reorganização das suas forças de dominação societal, não só procurando reorganizar em termos capitalistas o processo produtivo, mas procurando gestar um projeto de recuperação de hegemonia nas mais diversas esferas da sociabilidade. (ANTUNES, 2000, p. 48).

Entretanto, estes modelos de administração do trabalho foram criados com foco na indústria, que, na época, encontrava-se em ascensão e era a principal responsável pela geração de emprego. Hoje, esse modelo, apesar de ainda muito presente, conseguiu reduzir drasticamente o número de funcionários dentro do chão de fábrica e, paradoxalmente, aumentar a produção.

Diferente de muitos autores que acreditam que o toyotismo foi a solução para a crise do fordismo, Harvey (2000) afirma que a nova forma de acumulação de capital que surgiu com a crise do fordismo foi apenas um novo modo de regulação que ele denominou acumulação flexível. O autor ressalta que este novo modelo vem de encontro ao fordismo que era orientado pela rigidez tanto nas formas de investimento, como na sua atuação nos mercados e nas relações contratuais de trabalho. Assim, sempre que se tentava sobrepujar o problema da rigidez esbarrava-se na força da classe trabalhadora, o que gerou várias greves e problemas trabalhistas entre 1968 a 1973.

Havia problemas com a rigidez dos investimentos de capital fixo e de larga escala e de longo prazo em sistemas de produção em massa que impediam muita flexibilidade de planejamento e presumiam crescimento estável em mercados de consumo invariantes. Havia problemas na rigidez nos mercados, na alocação e contratos de trabalho (especialmente no chamado setor 'monopolista'). (HARVEY, 2000, p. 135).

A forma de acumulação flexível, que vem substituir um modelo de produção e acumulação ela- 
O IMPACTO DA ACELERAÇÃO | Osterne Filho et al.

borado sobre a ótica da rigidez produtiva, caracteriza-se por possuir maior flexibilidade nos processos de produção de bens; no mercado de trabalho, bem como nos produtos e padrões de consumo.

Como resultado deste modelo houve o surgimento de novos setores de produção, novas formas de serviços financeiros, novos mercados e, principalmente, taxas reforçadas de inovação comercial e tecnológica. Acredita-se que com esse modelo o sistema produtivo consiga operar dentro de contexto que exija rápidas mudanças, adaptando-se sempre às variações das demandas. Isto ocorre, pois, com a ajuda da tecnologia produtiva (automação, robôs), diminui-se o tempo de giro que é reduzido tanto da produção como do consumo. Produtos que antes as pessoas levavam sete anos para renovar, agora podem ser trocados em dois anos, atingindo até mesmo os bens culturais, fato que se denominou obsoletismo programado (SEVERIANO, 2007).

Com as mudanças geradas naquilo que alguns teóricos da sociologia chamaram de pós-modernidade e o novo modelo de acumulação de capital, percebe-se uma tendência ao decréscimo da mão de obra nas fábricas (proletariado fabril) e um incremento no setor de serviços que, segundo Antunes (2000), são aqueles trabalhadores inseridos em bancos, turismo, comércio, serviço público e até mesmo dentro das fábricas, mas na área administrativa. Some-se a isso o fato de que a acumulação flexível promove também desigualdades nos ritmos de desenvolvimento dos diversos setores produtivos e regiões geográficas.

Devido a ampliação do movimento de emprego no setor de serviços, há um estreitamento temporal nas tomadas de decisões, privadas e públicas, facilitadas pela comunicação via satélite e a redução nos custos de transportes, ou seja, a diminuição do tempo para levar a informação de um lugar para outro. Harvey (2000) define este fenômeno de compressão espaço-tempo.

Percebe-se que as mudanças geradas por esta nova forma de acumulação de capital, no que diz respeito aos trabalhadores, são a flexibilidade nos contratos de trabalho, o avanço do trabalho temporário, a diminuição de trabalhadores de tempo integral, a subcontratação, a terceirização, a precarização da mão de obra, o aumento do desemprego estrutural e o enfraquecimento dos sindicatos.

No que se refere à organização industrial, as mudanças estão ligadas à então mencionada diminuição do tempo de giro e de circulação das mercadorias em razão das intensidades das inovações lançadas no mercado. Isso fez com que se aumentassem o uso de novas tecnologias de automação e a dispersão espacial das fábricas pelo mundo, ocasionando uma descentralização da produção. Acarreta que a impressão residente de tais eventos, de acordo com Bauman (2000) é inebriante, uma vez que as transformações envelhecem e desaparecem em uma velocidade jamais experimentada. Pode-se falar em anos e não em décadas.

\section{4 | O TEMPO E O ESPAÇO NAS RELAÇÕES DE PRODUÇÃO}

Newton acreditava que a única característica diferente no tempo quando comparado aos demais objetos da natureza era o fato de não ser perceptível, mas em geral pensava-se no tempo como um dado objetivo do mundo criado, igual a todos os outros elementos da natureza. Por outra linha, Descartes e Kant pensavam o tempo e o espaço como dados a priori, ou seja, eles precedem qualquer experiência particular do sujeito, sendo um dado inato e não modificável da natureza humana.

Segundo Hawking (apud VERGARA; VIEIRA, 2005), até 1915, quando surgiu a teoria da relatividade de Einstein, acreditava-se que o tempo era independente do espaço. A partir da teoria einsteiniana, o tempo e o espaço deixaram de ser vistos como fenômenos isolados, e passaram a ser um contínuo tempo-espaço. Não se pode falar de situações isoladas no tempo ou no espaço, 
O IMPACTO DA ACELERAÇÃO | Osterne Filho et al.

e sim de ocorrência espaço-temporal.

Para Harvey (2000), o tempo e o espaço são categorias básicas para a existência humana, porém dificilmente discute-se sobre seus sentidos, mas tende-se a pensá-los com base no senso comum, como referências de valor natural e universal.

Os sentidos destas categorias podem variar geográfica e historicamente, entendendo que "[...] o tempo social e o espaço social são construídos diferencialmente" (HARVEY, 2000, p. 189). Isto acarreta a introdução de ideias particulares no entrelaçamento do tempo e do espaço com os modos de produção e a formação social vigente. Pode-se afirmar que tempo e espaço são categorias construídas que se desenvolvem em determinado momento e espaço históricos.

Por sua vez, Foucault (1984) defendia que o espaço seria então, mais portador de história que o tempo, mesmo que em nossa sociedade atual possamos conviver com uma aceleração do tempo tão nova quanto bem perceptível. Deste modo, a época contemporânea veria a predominância do espaço (talvez pela compressão do tempo), que se apresenta em relações que ele denominava posicionamentos, compreendidos como espaços de redes, de relações e de vizinhança, enfim de proximidade. Um espaço tido como heterogêneo compreenderia uma teia de relações que circunscrevem a totalidade de tudo o que existe. Seja no espaço cósmico do caos, seja na atual manifestação do capitalismo flexível ou desorganizado.

Enquanto isso, para Chartier (1990) a representação é uma emergência do passado no presente, a presentificação de um ausente, um apresentar de novo, que dá a ver uma ausência. Trata-se de trazer o passado para o presente como um ausente vivido, para apropriar-se dele, interpretá-lo. É construir, nas palavras do próprio Chartier (1990, p. 26) "uma história social das interpretações, remetidas para suas determinações fundamentais, que são o social, o institucional e, sobretudo, o cultural."

Lembre-se com Le Goff (1990) que a oposição entre passado e presente não é um dado natural, mas, sim, uma construção. Esse passado muda de acordo com as épocas e que tanto os historiadores quanto o homem comum estão submetidos ao tempo em que vivem. Neste caso, para o autor, é o caso de se compreender o passado pelo presente.

Conforme o entendemos, não é possível compreender o tempo e o espaço separados da ação social, podendo-se, assim, correlacioná-los às relações de poder. Ao passo, porém, em que se entende o tempo e o espaço como produtos e produtores de ações sociais, percebe-se, também, que estes são efeitos e fontes de poder social.

Em diferentes épocas históricas, correspondentes ao contexto dos vários modos de produção, o desenvolvimento das forças produtivas (meios de produção e força de trabalho) está intimamente ligado às relações de produção que o viabilizaram e permitem que se manifestem de forma mais ampla ou restrita. Para o marxismo, as crises em cada modo de produção marcam exatamente o descompasso entre o desenvolvimento das forças produtivas e as relações sociais de produção que o sustenta. A noção de contexto ligada à dimensão espacial e à noção de tempo articulada à perspectiva histórica é fundamental para a compreensão dialética que Marx (1997) faz do desenvolvimento humano na sua relação com o mundo e a natureza, enquanto capacidade de agir, produzir e transformar a natureza e a si mesmo.

No contexto da comuna primitiva do homem pré-histórico o tempo, o espaço, a natureza e o grupo social formam uma unidade onde o presente é a realidade predominante e o espaço está limitado à realidade de pequenos grupos sociais. Em uma tribo ou nas antigas sociedades humanas o tempo é marcado pelos ciclos naturais e os deslocamentos são limitados ao espaço alcançável por meios de transportes ainda muito rudimentares. Tal realidade não é casual, embora seu desenvolvimento não seja correspondente a uma lógica linear, pois há momentos revolucionários em diferentes épocas da história humana. 
O IMPACTO DA ACELERAÇÃO | Osterne Filho et al.

No feudalismo, por exemplo, o modo de produção e as relações de produção a ele correspondentes são marcados por uma estrutura social extremamente fechada e pouco flexível. Neste tipo de economia, baseada na posse da terra onde as relações sociais eram fundamentadas no dom e no contra-dom (HARVEY, 2000) e onde praticamente não havia mobilidade entre as classes sociais, o tempo era lento, marcado pelas estações e pelas guerras, o espaço não ia muito além das vilas e dos castelos e por poucas lutas que podiam superar seus limites, como as cruzadas ou a eterna ameaça de um inimigo externo.

Paradoxalmente, na antiguidade escravista, o deslocamento necessário para a conquista de novas colônias e escravos permitiam a ampliação dos espaços e das trocas culturais. Mas a terra imperial era o centro do mundo para a qual todas as conquistas retornam, pois a produção da riqueza era baseada, em última instância, no saque da acumulação primitiva produzida em cada local conquistado (PONCE, 2001).

Até a modernidade e ao correspondente desenvolvimento capitalista há algumas coisas em comum: no mundo pré-moderno o desenvolvimento das forças produtivas ainda não permitiam certa independência do homem com relação ao poder das forças naturais; o homem estava submetido à natureza e não o contrário, onde a natureza está submetida ao homem; na ontologia antiga há certo panteísmo, onde homem e natureza formavam um contínuo, vida e morte se encontravam, vida terrena e vida pós-morte se complementavam. Assim, tempo e espaço eram cíclicos, mas dependiam fundamentalmente de forças divinas ou naturais.

Na modernidade, tempo e espaço começam a se acelerar, pois agora depende não de forças divinas, mas das próprias capacidades humanas: o desenvolvimento crescente das forças produtivas permite o controle das forças naturais; o desenvolvimento do comércio atinge fronteiras antes inimagináveis, mas agora controláveis por meios de deslocamentos mais seguros e relações sociais mais permanentes; o trabalho já não está mais estreitamente relacionado à posse da terra e seus ciclos naturais e a conquista imperial de novas terras podem ser mantidos para além do saque ocasional das novas colônias e de sua acumulação primitiva. De fato, no capitalismo monopolista nascente o desenvolvimento das forças produtivas e suas novas tecnologias permitem a exploração espaço-temporal de forma mais permanentes e duradouros marcada por novas relações de produção correspondentes a essa fase de desenvolvimento da humanidade: a compra e a venda da força de trabalho pelo capital.

Tempo e espaço não são mais cíclicos e ocasionais, marcado pela inflexibilidade dos ciclos da terra ou pelas guerras de conquistas, mas agora permanentes, flexíveis e amplos, pois nessa nova lógica o domínio das forças naturais, especialmente com o desenvolvimento da indústria moderna, permite não só o controle mais ou menos estável das forças naturais e o desenvolvimento das relações sociais que as mantêm, mas remontar o tempo e o espaço em uma nova unidade: agora controlada pelos arbítrios do capital. De fato, a modernidade funda-se no lastro do mecanicismo cuja máquina-metáfora é o relógio e seus ciclos tipicamente humanos, embora inspirados no funcionamento da natureza, dos dias e das estações.

Neste sentido, retornando a Foucault (1984), ocorre hoje a mencionada oposição, dizendo melhor, diferenciação, entre tempo e espaço. Trata-se no caso de um movimento relacional não mutuamente excludente. Para o autor, o espaço estaria relacionado às mudanças, tanto no universo cósmico quanto no social, referindo-se aos confrontos de ideias e a consciência de novas representações.

Quanto ao tempo, ele seria o momento das narrativas, ganhando importância com a estabilidade. Dizemos de nós seja quando falamos de corpos acomodados em órbitas celestes, quanto em estruturas de poder em arranjos sociais complexos. Nesse caso, sempre em relação e associação a uma identidade dominante. Viveríamos assim, numa época da simultaneidade, uma es- 
O IMPACTO DA ACELERAÇÃO | Osterne Filho et al.

pécie de justaposição de eventos, numa relação atualizada e de aproximação entre o próximo e o longínquo. Tomando um exemplo atual, pode-se mencionar os movimentos de rebeldia e revolta no pós-crise econômica de 2008 que ocorrem num lapso de tempo relativamente próximo, mas em lugares distantes. Esse foi o caso do movimento ocupem Wall Street nos EUA, da primavera árabe, ou ainda das manifestações em países tão diversos quanto a Turquia, a Jordânia, a Venezuela, a Ucrânia, e o Brasil, por exemplo.

$\mathrm{Na}$ origem da modernidade para Galileu o espaço era o da extensão, do universo infinito. Antes, na idade média, separavam-se os corpos celestes dos terrestres. Nos dias hodiernos, viveríamos um espaço de posicionamento, a partir de relações de vizinhança entre os elementos, pontos esses descritos como séries, organogramas, grades (FOUCAULT, 2001).

$\mathrm{Na}$ atualidade, há uma preocupação maior com o tempo e com medidas temporais. Segundo Elias (1984), isto ocorre por conta da urbanização, da mecanização e da comercialização. Para o autor, quanto mais a sociedade evolui, mais os indivíduos ficam presos ao tempo. A medição cronológica permitiu ao homem possuir regularidade e controle, diante de todo movimento da vida, de forma que as pessoas organizam e programam seus dias em função deste, possibilitando uma maior previsibilidade do cotidiano.

Acredita-se assim, que o tempo deva ser entendido dentro do contexto social onde é produzido e também, em interação com outros elementos da vida social, sendo que este guarda valores simbólicos relacionados às ações humanas e suas instituições. Além do que, isso permite que os homens situem-se e posicionem-se diante de toda sorte de acontecimentos, prevenindo-se paradoxalmente do contingencial, com a regularidade que a invenção do relógio nos permitiu. Se a percepção de tempo é um produto social, a compreensão de espaço segue os mesmos ditames e possui idêntica relevância. Bauman (1999, p. 19) diz que a "distância é um produto social; sua extensão varia dependendo da velocidade com a qual pode ser vencida".

$\mathrm{Na}$ sociedade capitalista o modelo de tempo criado influencia os modos de subjetivação, recebendo, inclusive, o valorativo de commodities (TURNBULL, 2004). Desde cedo, quando a identidade está sendo constituída, o indivíduo é ensinado sobre o tempo. Este, por seu turno, é marcado pelos calendários, relógios e horários, e caracteriza uma "coação social". Tal coação que se inicia externamente e que faz parte dos os momentos da vida dos indivíduos acaba por ser incorporada como elemento cognitivo, transformando-se em autocoação.

$\mathrm{Na}$ atual sociedade os indivíduos desenvolvem uma consciência temporal "enraizada, global e onipresente" (ELIAS, 1984, p.32). Parece que as preocupações constantes com o tempo, em uma vida onde tudo depende de horários, caracteriza uma dependência cada vez maior de um tempo que parece passar cada vez mais rápido.

Harvey (2000), diz que quem tiver dinheiro consegue dominar "melhor" o tempo (o próprio e de outras pessoas) e o espaço, ao passo que conseguir dominá-los pode auxiliar a dominar o dinheiro. Desta forma, entra-se em um ciclo de poder, onde quem tem dinheiro define tempo e espaço e quem define tempo e espaço tem poder sobre o dinheiro.

Se dinheiro, espaço e tempo estão interligados, não há como fugir ao impacto das determinações do capital sobre o tempo e o espaço. Uma vez que a lógica capitalista acredita que quanto mais célere é o ciclo de investimento e recuperação do capital investido, maior pode ser o lucro. Isso acarreta numa aceleração dos processos, não só produtivos, mas na reconstrução do modelo de espaço, acabando com as barreiras que possam impedir a rápida circulação de informações, bens e serviços.

Com a quebra de barreiras espaço-temporais e a flexibilização das relações, fica mais fácil para os investidores controlarem as organizações a qualquer distância que estejam delas. Estes podem mudá-las para qualquer lugar que considerem mais lucrativos e não sofrerão nada com 


\section{O IMPACTO DA ACELERAÇÃO | Osterne Filho et al.}

isto, tal escolha será sempre pautada no lucro.

Cabe a eles, portanto, mover a companhia para onde quer que percebam ou prevejam uma chance de dividendos mais elevados, deixando a todos os demais - presos como são à localidade - a tarefa de lamber as feridas, de consertar o dano e se livrar do lixo. (BAUMAN, 1999, p. 15).

O respeito aos indivíduos - trabalhadores, fornecedores e até mesmo aos governos - que ajudam a construir grandes organizações, parece agora ser o menos importante diante da aceleração tempo-espaço, flexibilização do capital e a quebra de barreiras. Quando grandes investidores são forçados a se preocuparem com tais indivíduos e tomar decisões pensando nestes outros, é mais fácil se mudar para locais menos resistentes, ou seja, locais onde a exploração apresenta menos barreiras, ou até mesmo nenhuma.

O que vemos na atualidade é um modelo de tempo acelerado, onde cada minuto é precioso para ganhar dinheiro, e um espaço sem barreiras é fundamental no cenário capitalista. Harvey (2000, p. 219), afirma que vem ocorrendo a compressão do tempo-espaço, pois o mundo vem encolhendo e se tornando uma "aldeia global de telecomunicações [...] e os horizontes temporais se reduzem a um ponto em que só existe o presente."

$\mathrm{Na}$ antiguidade existia a dificuldade de locomoção em razão dos meios de transportes primitivos, que dificultavam as viagens. Hoje, com o domínio tecnológico os protecionismos foram quebrados, e não existem mais fronteiras geográficas (WARF, 2011). Esta locomoção rápida, principalmente dos corpos, é mais eficiente quando existe um alto investimento. A elite, detentora do capital, é capaz de se locomover pelo globo de forma que não existe "perto" nem "longe".

Mais rápido do que a viagem dos corpos é a viagem da informação. Com o desenvolvimento da tecnologia e sua constante atualização, os indivíduos encontram-se a "uma mensagem" de distância, uns dos outros, independente do local do mapa em que estejam, vivendo em uma espécie de espacialidade temporal.

A separação dos movimentos da informação em relação aos movimentos dos seus portadores e objetos permitiu por sua vez a diferenciação de suas velocidades; o movimento da informação ganhava velocidade num ritmo muito mais rápido que a viagem dos corpos ou a mudança da situação sobre a qual se informava. (BAUMAN, 1999, p. 21-22).

Entendendo que tempo-espaço é construído socialmente e que o uso de novas tecnologias, o modo de produção, as formas de se relacionar na sociedade, entre outras coisas, afetam a forma como se experiencia essas categorias, pode-se perceber que a mudança do fordismo de inspiração keynesiana para a acumulação flexível impactou, substancialmente, a relação indivíduo-tempo-espaço. Tal mudança só foi possível face a rápidas alterações que ocorreram nas formas organizacionais e nas tecnologias produtivas decorrentes de certo modo do desenvolvimento das forças produtivas, que vem permitindo, inclusive, maior sobrevida ao capital em crise.

Entre as principais mudanças advindas da acumulação flexível estão: a aceleração do tempo de giro da produção, que significa uma diminuição no tempo de produção das mercadorias (aumento de produtividade); a distribuição e a implantação de estratégias logísticas de diminuição de estoque; lançamento contínuo de novos produtos, diminuindo o tempo de uso de um produto, para gerar a compra de um novo; e o movimento para a desintegração vertical que, segundo Abramczuk (2001), significa a diminuição na cadeia produtiva das empresas, que pode ser tanto dos processos como de postos de trabalhos. Ao invés da integração vertical, bastante praticada no fordismo, a ideia é integrar à indústria a atividade de terceiros que estão bastante ligadas ao segmento industrial terceirizado.

Tais mudanças acarretaram para os trabalhadores, segundo Harvey (2000, p. 256), "[...] uma 
O IMPACTO DA ACELERAÇÃO | Osterne Filho et al.

intensificação dos processos de trabalho e uma aceleração na desqualificação e requalificação necessários ao atendimento de novas necessidades de trabalho". A partir deste momento, não basta aos trabalhadores saberem fazer somente uma atividade, como faziam nas linhas de montagem, eles precisam saber e entender o processo de forma sistemática em que tempo e espaço parecem se unificar.

\section{5 | CONSIDERAÇÕES FINAIS}

Através de uma leitura cuidadosa dos modos de produção foi possível visualizar o impacto dos fenômenos tempo e espaço causado nas relações de produção, notadamente no atual contexto de reestruturação produtiva do capital em crise.

A compressão tempo-espaço está de acordo com a aceleração dos processos globais, de tal maneira que se sente as distâncias se encolhendo; o mundo parece menor e acontecimentos em determinados lugares impactam imediatamente em pessoas e lugares distantes.

Pensando a identidade como um processo socialmente construído, é fácil perceber como a compressão tempo-espaço impacta na (re)construção da identidade cultural, uma vez que os sujeitos encontram-se cada vez mais próximos de diversas culturas, em um espaço de tempo cada vez menor.

Embora aparentemente possibilite ao capital ampliar as estratégias defensivas do capital em crise, as implicações da aceleração e da compressão tempo-espaço produz marcas psíquicas intensas sobre os sujeitos: desterritorilização, descontextualização e alienação temporal, gerando sofrimento psíquico e perda de limites relacionais.

Desta forma o fenômeno da aceleração tempo-espaço contribui para o enfraquecimento da identidade cultural, ou seja, no esmaecimento da identificação com o lugar em que se nasceu e se criou, pois, o espaço não pode ser mais definido como fixo, e a mudança do tempo faz com que todas as pessoas tenham acesso a outros lugares, mesmos distantes, quase que instantaneamente. É difícil manter uma identificação fixa, quando tudo ao redor é móvel e, como nos lembra Marx "tudo que é sólido de desmancha no ar". Só o tempo nos dirá que espaço ocuparemos no futuro. 
O IMPACTO DA ACELERAÇÃO | Osterne Filho et al.

\section{Referências}

ABRAMCZUK, André Ambrósio. Os relacionamentos na cadeia de suprimentos sob o paradigma da desintegração vertical de processos: um estudo de caso. 2001. 193 f. Dissertação (Mestrado em Engenharia) - Escola Politécnica, Universidade de São Paulo, São Paulo, 2001.

ANTUNES, Jair. Marx e o último Engels: o modo de produção asiático e a origem do etapismo na teoria da história marxista. In: COLÓQUIO INTERNACIONAL MARX E ENGELS, 5., 2007, Campinas. Anais... Campinas: UNICAMP /CEMARX, 2007.

ANTUNES, Ricardo. Os sentidos do trabalho: ensaio sobre a afirmação e a negação do trabalho. São Paulo: Boitempo, 2000.

BAUMAN, Zygmunt. Globalização: as consequências humanas. Rio de Janeiro: Jorge Zahar, 1999.

Em busca da política. Rio de Janeiro: Zahar, $\overline{2} \overline{0} \overline{0}$.

BHABHA, Homi. Nazione e narrazione. Roma: Meltemi, 1997.

CASTELLS, Manuel. Comunicación móvil y sociedad: una perspectiva global. Madrid: Siglo XXI, 2006.

CHARTIER, Roger. A história cultural: entre práticas e representações. Lisboa: Difel, 1990.

ELIAS, Norbert. Sobre o tempo. Rio de Janeiro: Jorge Zahar, 1984.

ENGELS, Friedrich. A origem da família, da propriedade privada e do Estado. Rio de Janeiro: Civilização Brasileira, 1987.

FERNANDES, Florestan. Marx, Engels, Lenin: a história em processo. São Paulo: Expressão Popular, 2001.

FOUCAULT, Michel. Ditos e escritos. Rio de Janeiro: Forense Universitária, 2001. v. 3.

Sobre a geografia. In: FOUCAULT, Michel. Microfísica do poder. Organização de Roberto Machado. Rio de Janeiro: Graal, 1984.

HALL, Stuart. A identidade cultural na pós-modernidade. Rio de Janeiro: DP\&A, 1992.

HARVEY, David. Condição pós-moderna. São Paulo: Loyla, 2000.
LE GOFF. Jacques. História e memória. Campinas: UNICAMP, 1990.

LESSA, Sérgio; TONET, Ivo. Introdução à filosofia de Marx. São Paulo: Expressão Popular, 2008.

MARX, Karl. O método da economia política: terceira parte da "Introdução [à crítica da economia política]". São Paulo: IECH; UNICAMP, 1997.

MARZZITELLI, Edna. Conhecendo o materialismo histórico e o marxismo: conhecendo Marx. In: ENCONTRO BRASILEIRO DE EDUCAÇÃO E MARXISMO, 5., 2011, Florianópolis. Anais... Florianópolis: ABEM, 2011.

MENEGASSO, Maria Ester. O declínio do emprego e a ascensão da empregabilidade: um protótipo para promover condições de empregabilidade na empresa pública do setor bancário. 1998. Tese (Doutorado) Universidade Federal de Santa Catarina, Santa Catarina, 1998.

PONCE, Aníbal. Educação e luta de classes. São Paulo: Cortez, 2001.

SANTOS, Milton. Modo de produção técnico científico e diferenciação espacial. Revista Território, v. 4, n.6, p. 5-20, 1999.

SEVERIANO, Maria de Fátima Vieira. Narcisismo e publicidade: uma análise psicossocial dos ideais do consumo na contemporaneidade. São Paulo: Annablume, 2007.

TENÓRIO, Fernando Guilherme. A unidade dos contrários: fordismo e pós-fordismo. Revista de Administração Pública, v. 45, n. 4, p. 1141-1172, 2011.

TURNBULL, Sharon. Perception and experience of time-space compression and acceleration: he shaping of leaders' identities. Journal of Managerial Psychology, v. 19, n. 8, p. 809-824, 2004.

VERGARA, Sílvia Constant; VIEIRA, Marcelo Milano Falcão. Sobre a dimensão tempo-espaço na análise organizacional. Revista de Administração Contemporânea, v. 9, n. 2, p. 103-119, 2005.

WARF, Barney. Excavating the prehistory of time-space compression. The Geographical Review, v. 101, n. 3, p. 435-467, 2011. 